\title{
Digital human models
}

\section{Gregory C. Smith*}

CE Engineering, 1380 NE Airport Way,

Suite K79464, Portland, Oregon 97230, USA

Email: gsfsmith@msn.com

*Corresponding author

\section{Shana S. Smith}

Department of Mechanical Engineering,

National Taiwan University,

No. 1, Section 4, Roosevelt Road,

Taipei City, 10617, Taiwan

Email:ssmith@ntu.edu.tw

\begin{abstract}
This study describes digital human models. This study also describes trends in digital human models, shows that the most important trend in digital human models is integrated digital human models, shows that integrated digital human models are frameworks and models and describes frameworks and models that can be used to create digital human models. The results can be used to describe, select, or create digital human models.
\end{abstract}

Keywords: digital human models; integrated digital human models; frameworks; models.

Reference to this paper should be made as follows: Smith, G.C. and Smith, S.S. (2015) 'Digital human models', Int. J. Digital Human, Vol. 1, No. 1, pp.2-29.

Biographical notes: Gregory C. Smith is a Research Engineer at CE Engineering. His research interests include design methods, digital human models and robotics.

Shana S. Smith is a Professor in the Department of Mechanical Engineering at National Taiwan University. Her teaching and research interests include user-centred design, lifecycle design, engineering graphics, virtual reality and technology in education.

\section{Introduction}

Digital human models are becoming widely used in science, engineering and education. Digital human models can be used to study the relationships between environmental conditions and human responses, improve the usability, comfort and safety of products 
and increase the realism and accuracy of training systems. As a result, scientists, engineers and educators need information on digital human models.

This study describes digital human models. This study also describes trends in digital human models, shows that the most important trend in digital human models is integrated digital human models, shows that integrated digital human models are frameworks and models and describes frameworks and models which can be used to create digital human models.

Section 2 describes digital human models. Section 3 describes trends in digital human models. Section 4 presents conclusions. The results show that digital human models are models, programmes, or devices, theoretical, analytical, or physical models and behavioural, functional, or structural models. The results show that digital human models are integrated or individual models. The results can be used to describe, select, or create digital human models.

\section{Digital human models}

Digital human models are models of humans. Digital human models are models, programmes, or devices, theoretical, analytical, or physical models and behavioural, functional, or structural models. Digital human models are integrated or individual models.

\subsection{Three models}

Figures 1-3 show three models which are theoretical models.

Figure 1 A model which can be used to study human behaviours

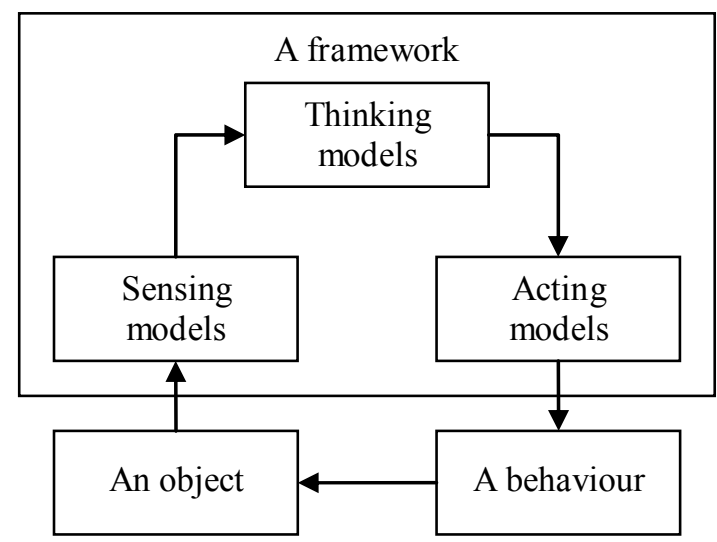

The model in Figure 1 is a behavioural model which can be used to study human behaviours. The model in Figure 1 is an integrated model which consists of a framework and sensing (seeing, hearing, touching, tasting, or smelling), thinking (communicating, remembering, deciding, solving, or learning) and acting (speaking, grasping, or moving) models (Carruth et al., 2007). 
Figure 2 A model which can be used to study human functions

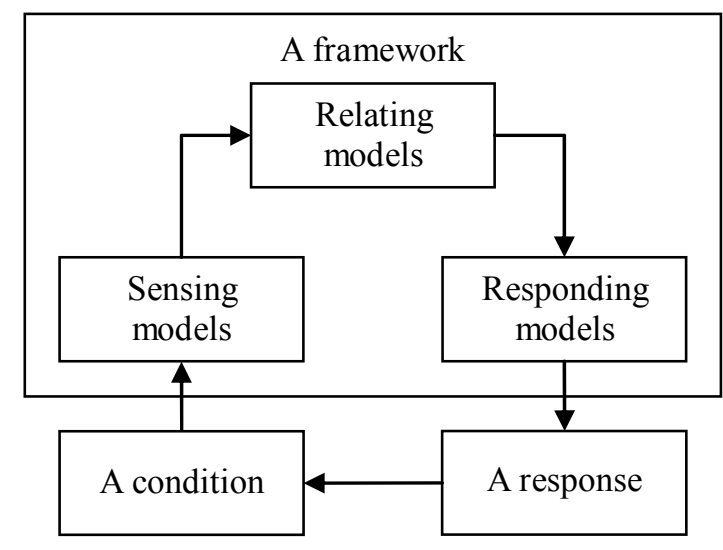

The model in Figure 2 is a functional model which can used to study human functions. The model in Figure 2 is an integrated model which consists of a framework and sensing (detecting, identifying, or measuring), relating (selecting, matching, or transforming) and responding (generating, or modifying) models (Miller et al., 2010; Noble et al., 2012).

Figure 3 A model which can be used to study human structures

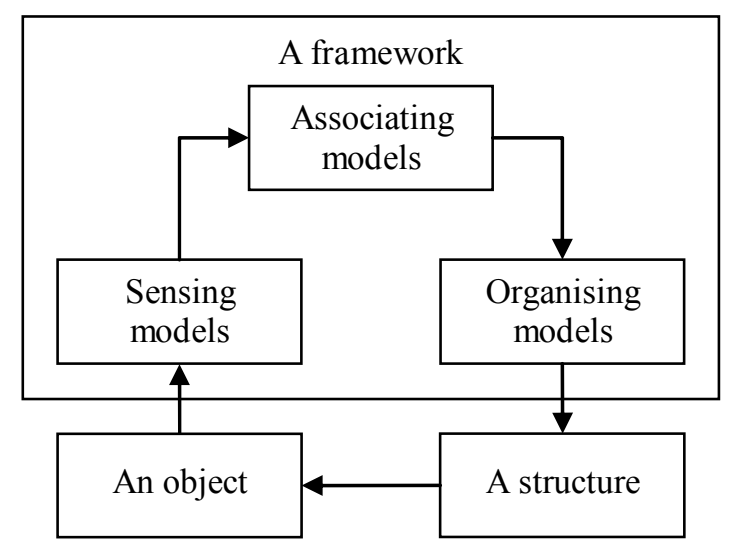

The model in Figure 3 is a structural model which can be used to study human structures. The model in Figure 3 is an integrated model which consists of a framework and sensing (experiencing, contacting, or receiving), associating (selecting, matching, or transforming) and organising (creating, or modifying) models (Smith and Yen, 2010).

\subsection{Three programmes}

Figures 4-6 show three programmes which are analytical models. 
Figure 4 A programme which can be used to analyse human bicycling behaviours (see online version for colours)

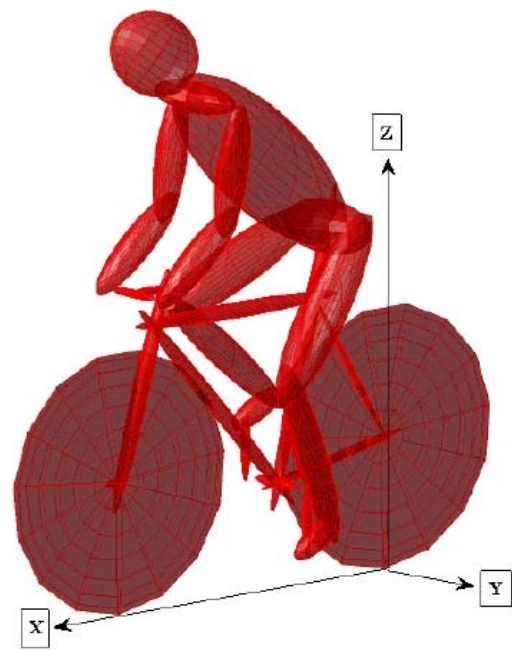

The programme in Figure 4 is a behavioural model which can be used to analyse human behaviours. The programme in Figure 4 is an integrated model which consists of a framework and sensing (seeing, hearing, touching, tasting, or smelling), thinking (communicating, remembering, deciding, solving, or learning) and acting (speaking, grasping, or moving) models (Cangley et al., 2012).

Figure 5 A programme which can be used to analyse human circulatory functions (see online version for colours)

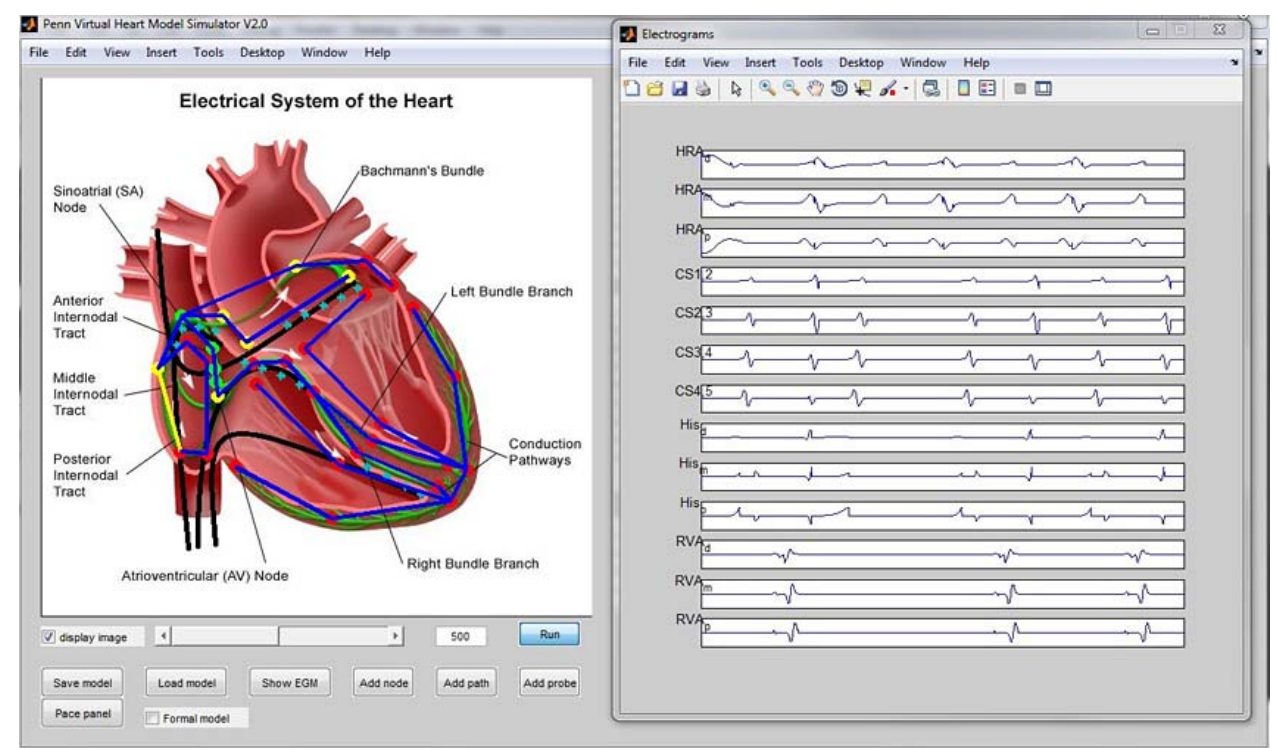


The programme in Figure 5 is a functional model which can be used to analyse human functions. The programme is an integrated model, which consists of a framework and sensing (detecting, identifying, or measuring), relating (selecting, matching, or transforming) and responding (generating, or modifying) models (Jiang and Mangharam, 2013).

Figure 6 A programme which can be used to analyse human atomic structures (see online version for colours)

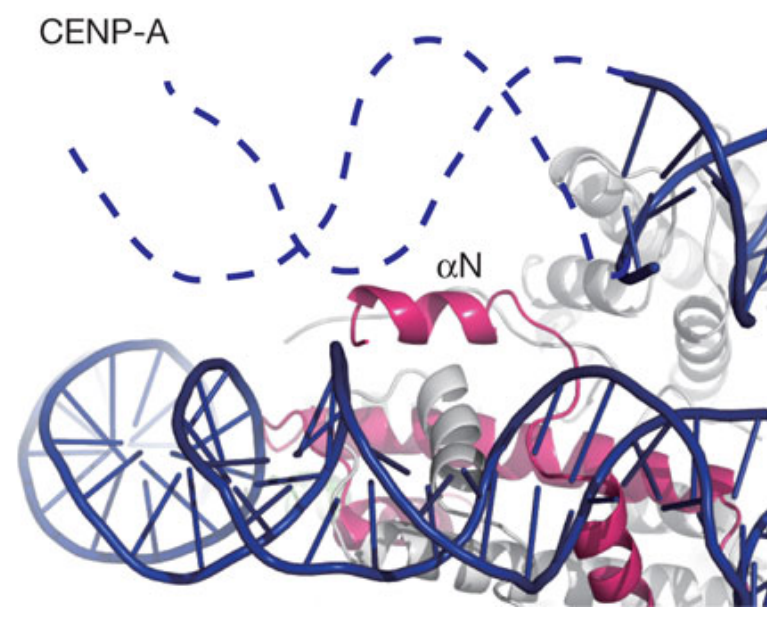

The programme in Figure 6 is a structural model which can be used to analyse human structures. The programme is an integrated model, which consists of a framework and sensing (experiencing, contacting, or receiving), associating (selecting, matching, or transforming) and organising (creating, or modifying) models (Tachiwana et al., 2011).

\subsection{Five devices}

Figures 7-11 show five devices which are physical models.

Figure 7 An automaton which can be used to duplicate human writing behaviours (see online version for colours)

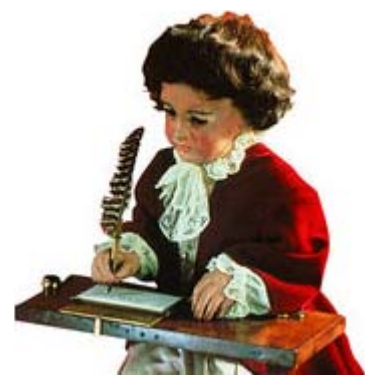


The devices in Figures 7-11 are behavioural models which can be used to duplicate human behaviours. The devices are integrated models which consist of frameworks and sensing (seeing, hearing, touching, tasting, or smelling), thinking (communicating, remembering, deciding, solving, or learning) and acting (speaking, grasping, or moving) models (Kolesnikov-Jessop, 2012; Waurzyniak, 2013; Rodic, et al., 2009; Iwata and Sugano, 2009; Mellman and Xu, 2010).

Figure 8 An industrial robot which can be used to duplicate human lifting behaviours (see online version for colours)

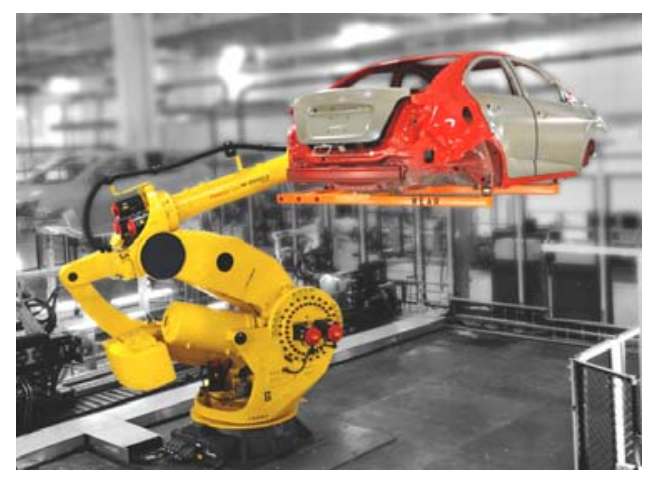

Figure 9 An agent-based robot which can be used to duplicate human monitoring behaviours (see online version for colours)

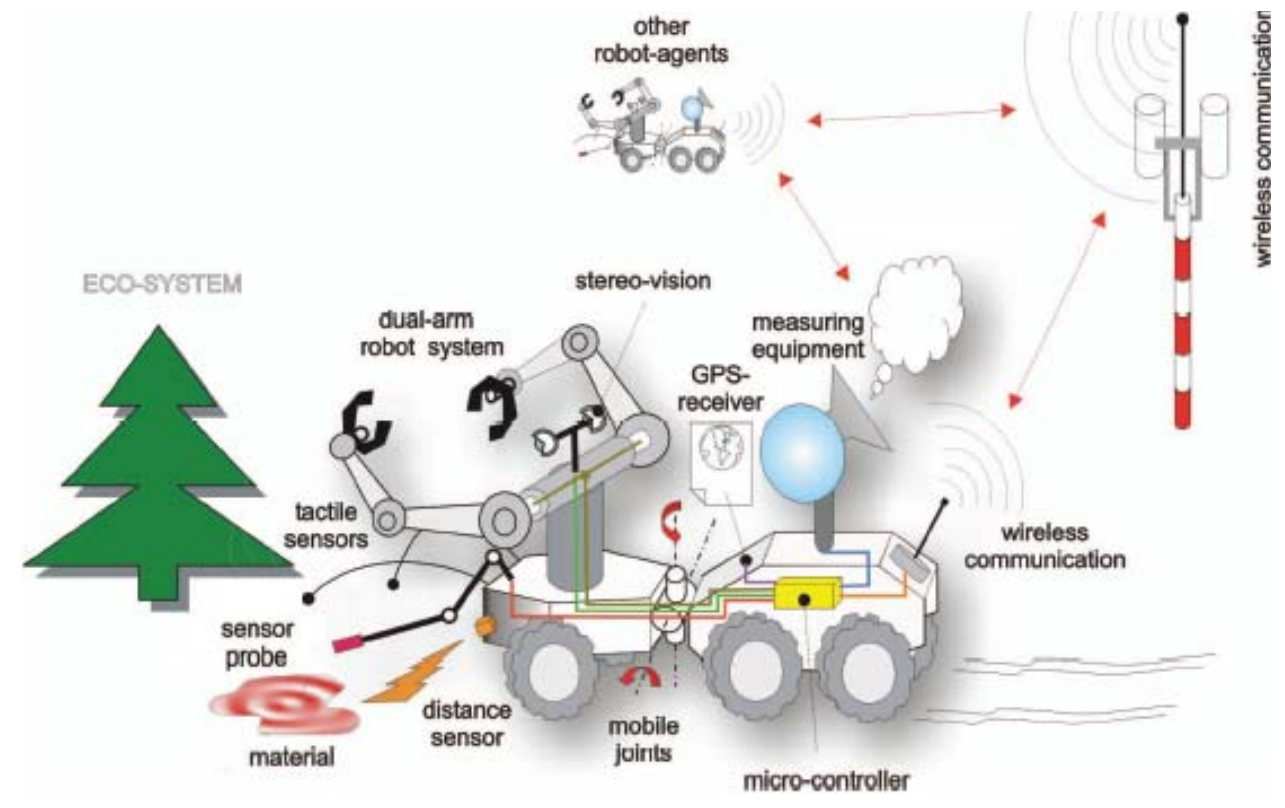


Figure 10 A service robot which can be used to duplicate human searching behaviours (see online version for colours)

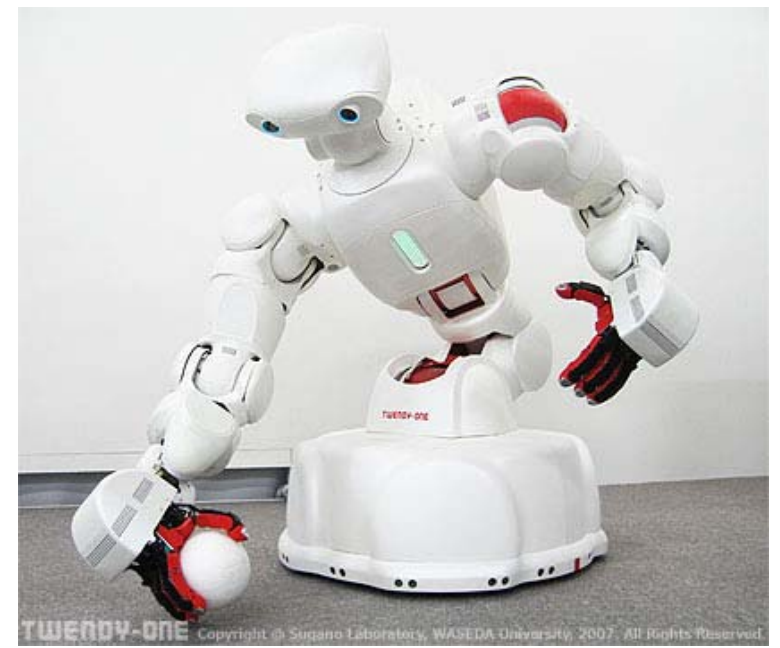

Figure 11 An intelligent robot which can be used to duplicate human playing behaviours (see online version for colours)

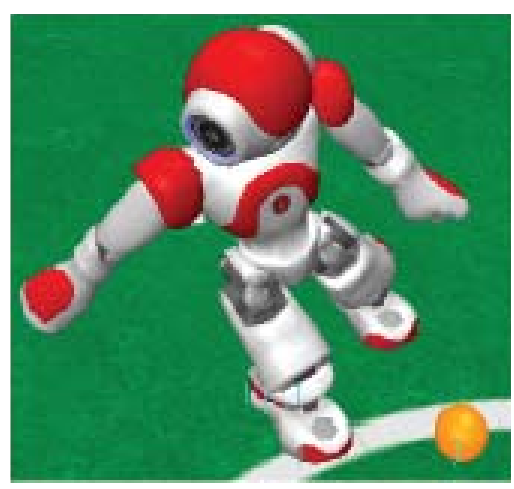

\section{Trends in digital human models}

Integrated models are the most important trend in digital human models. Integrated models consist of frameworks and models. Therefore, integrated models can be used to create simple, complex, or custom models. As a result, integrated models can be used to complete simple, complex, or custom tasks, with different levels of accuracy or computing time. 


\subsection{Three frameworks}

Figures 12-14 show three frameworks which can be used to create digital human models.

Figure 12 A framework which can be used to create behavioural models

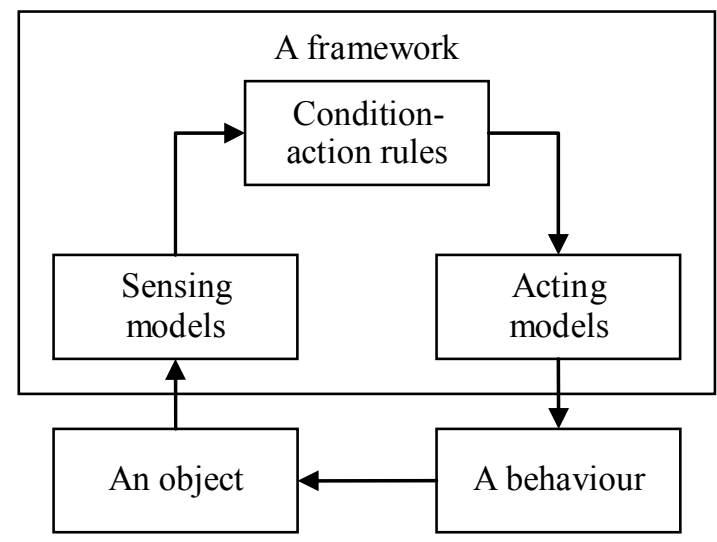

The framework in Figure 12 can be used to create behavioural models. The framework uses sensing (seeing, hearing, touching, tasting, or smelling), thinking (communicating, remembering, deciding, solving, or learning) and acting (speaking, grasping, or moving) models to create behavioural models. The thinking (communicating, remembering, deciding, solving, or learning) models use condition-action rules to model human thinking (Carruth et al., 2007).

Figure 13 A framework which can be used to create functional models

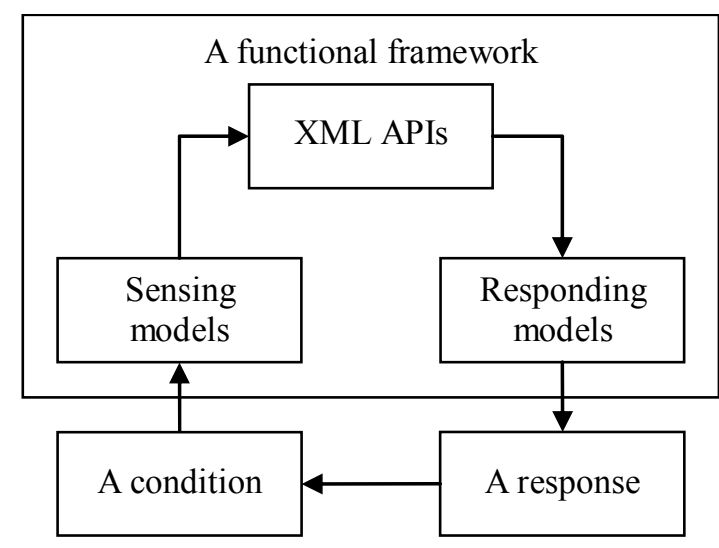

The framework in Figure 13 can be used to create functional models. The framework uses sensing (detecting, identifying, or measuring), relating (selecting, matching, or transforming) and responding (generating, or modifying) models to create functional models. The relating (selecting, matching, or transforming) models use XML APIs to model human relating (Miller et al., 2010; Noble et al., 2012). 
Figure 14 A framework that can be used to create structural models

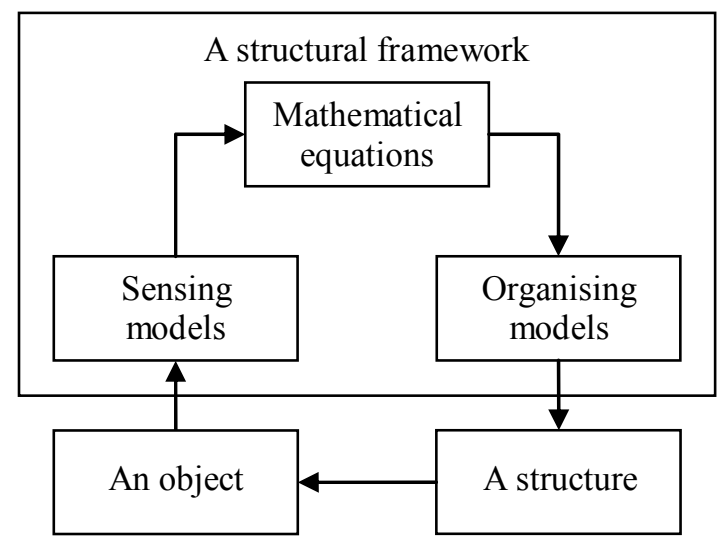

The framework in Figure 14 can be used to create structural models. The framework uses sensing (experiencing, contacting, or receiving), associating (selecting, matching, or transforming) and organising (creating, or modifying) models to create structural models. The associating models use mathematical equations to create structural models (Smith and Yen, 2010).

\subsection{Thirty models}

\subsubsection{Seventeen sensing models}

Figures 15-30 show 17 sensing (seeing, hearing, touching, tasting, or smelling) models which can be used to create digital human models.

Figure 15 A camera (see online version for colours)

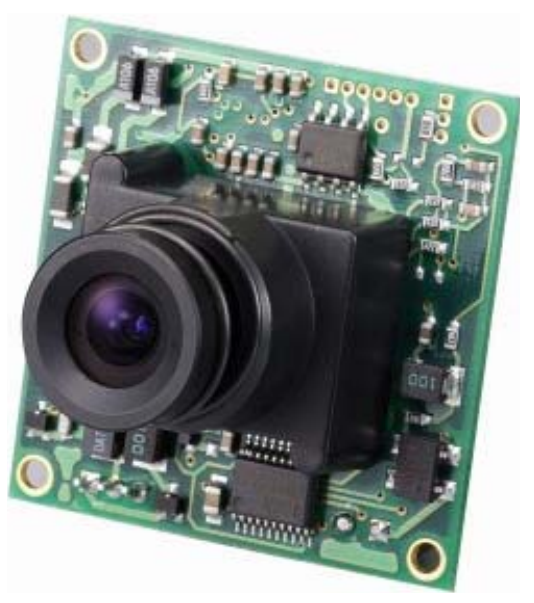

The seeing model in Figure 15 uses a camera to capture visible images. The camera uses a lens, an aperture and sensors to capture light, change focus, change focal length and capture visible images (Smith and Smith, 2011). 
Figure 16 A biomimetic eye (see online version for colours)
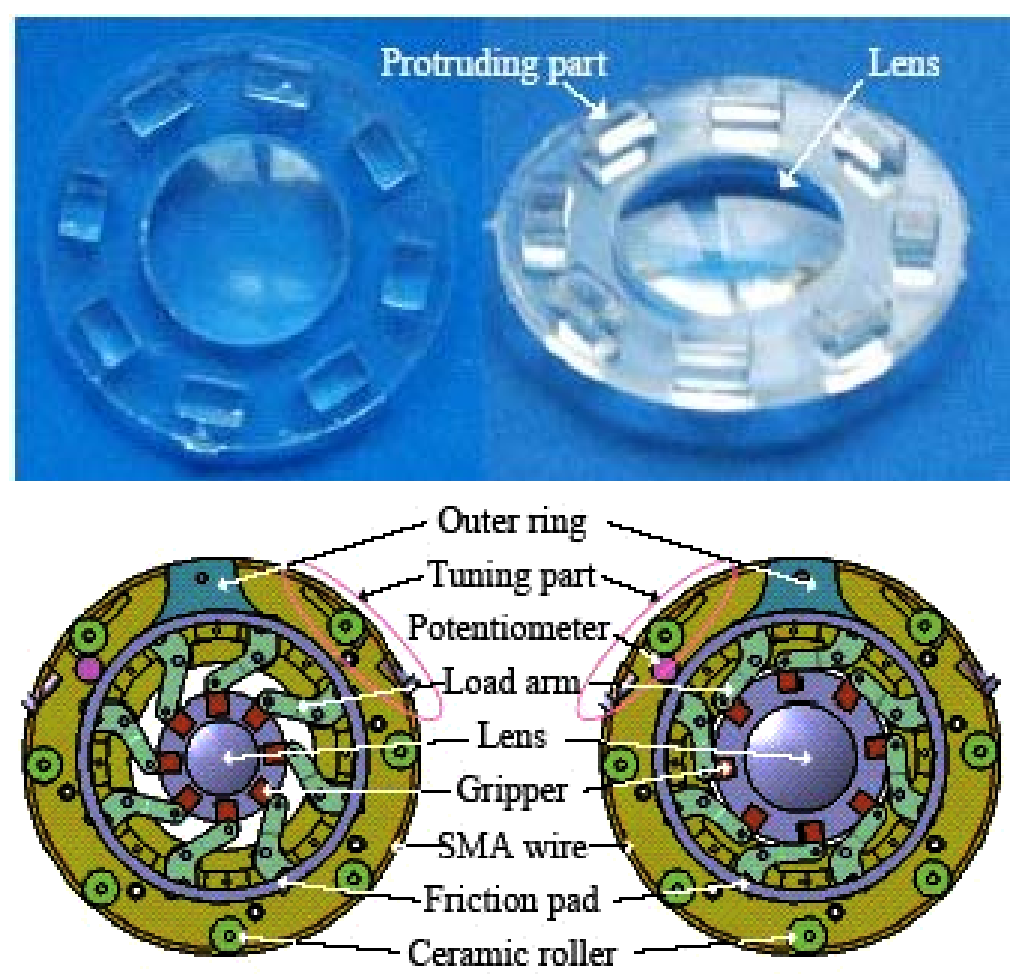

The seeing model in Figure 16 uses a biomimetic eye to capture visible images. The biomimetic eye uses a gel polydimethy-siloxane silicone (PDMS) lens, shape memory alloy (SMA) wires, grippers, load arms and an outer ring to capture light, change focus, change focal length and capture visible images (Choi et al., 2008).

Figure 17 An infrared camera (see online version for colours)

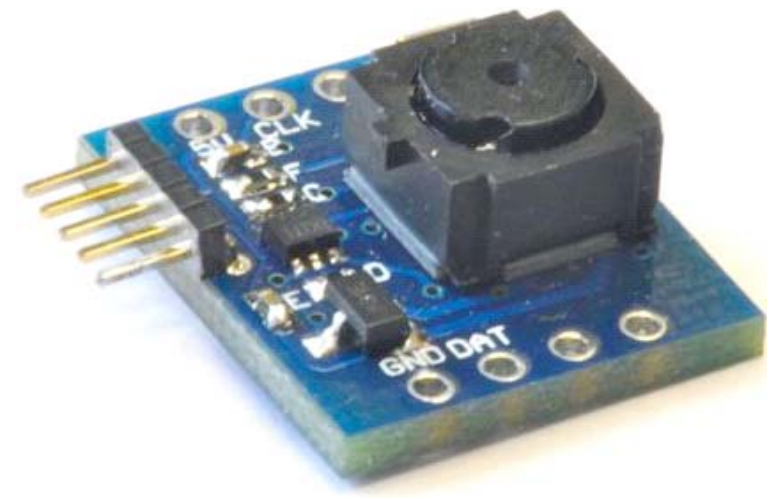

The seeing model in Figure 17 uses an infrared camera to capture infrared images. The infrared camera uses a fixed-focus lens and infrared sensors to capture infrared light and capture infrared images (Kao and Smith, 2011). 
Figure 18 An object-recognition algorithm

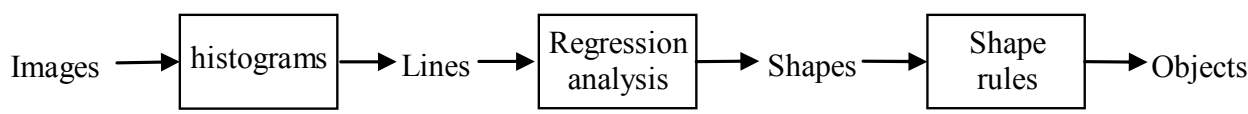

Figure 19 Two-dimensional objects in an image

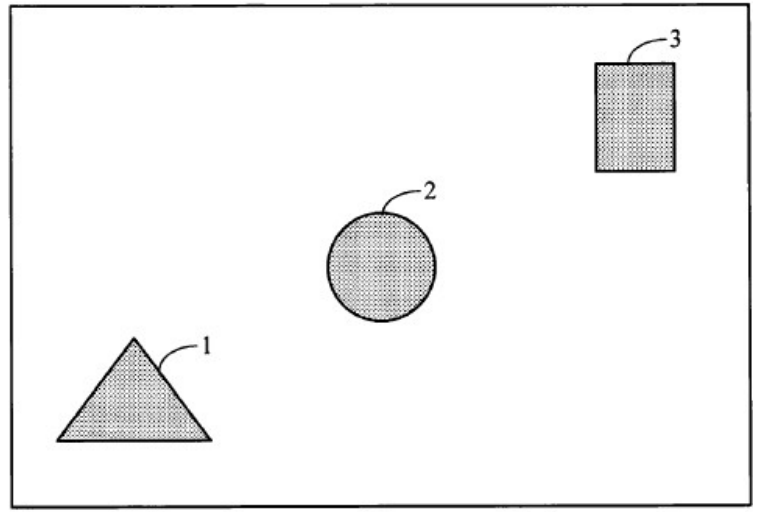

Figure 20 Histograms of two-dimensional objects in an image

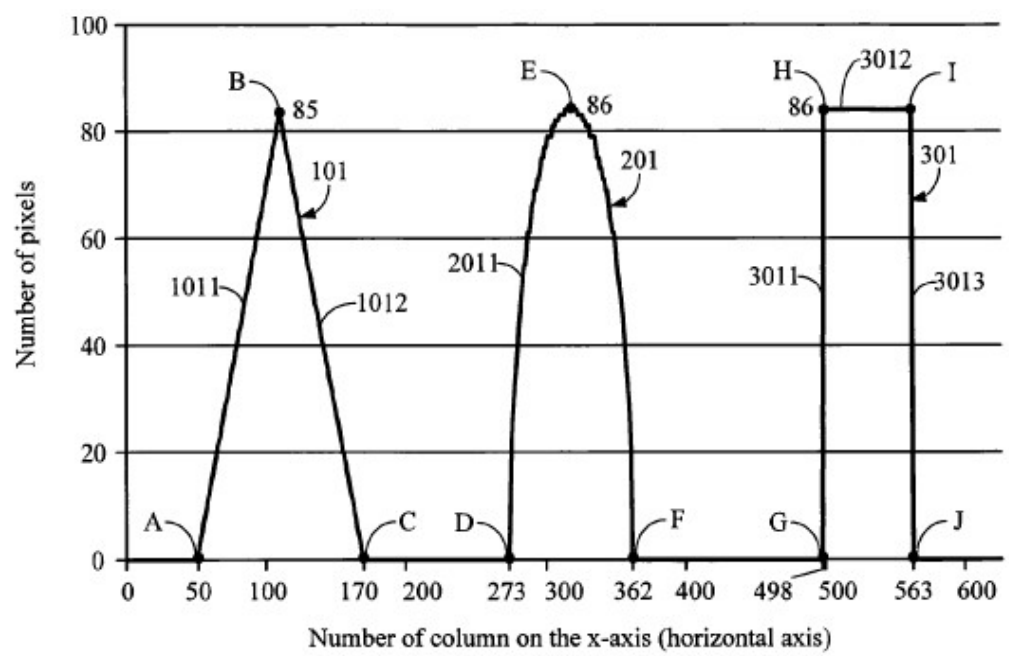

The seeing model in Figures 18-20 uses an object-recognition algorithm to detect the shapes, sizes, locations and orientations of two-dimensional objects in images. The object-recognition algorithm uses histograms, regression analysis and shape rules to detect lines, detect shapes and detect the shapes, sizes, locations and orientations of two-dimensional objects in images (Smith and Smith, 2011).

Figure 21 A pattern-recognition algorithm

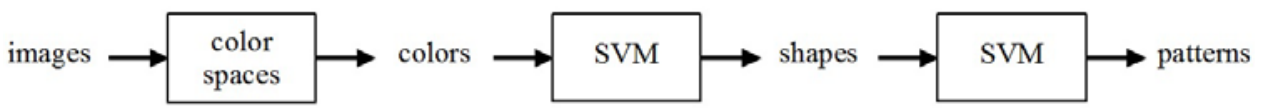


Figure 22 Four images of traffic signs (see online version for colours)
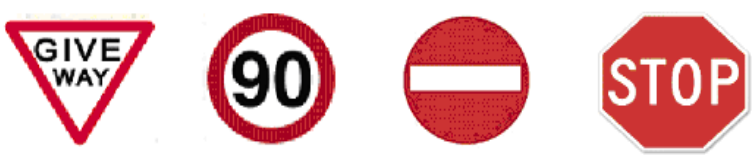

The seeing model in Figures 21-22 uses a pattern-recognition algorithm to detect patterns (words) in images. The pattern-recognition algorithm uses colour spaces and support vector machines (SVMs) to detect colours, detect shapes and detect patterns (words) in images (Maldonado-Bascon, 2007).

Figure 23 An object-reconstruction algorithm

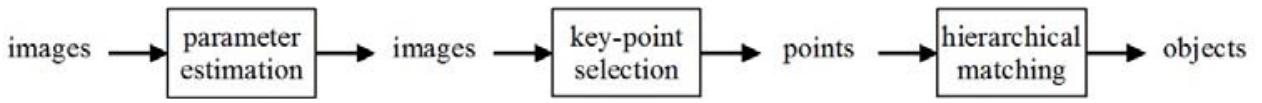

Figure 24 A three-dimensional object in images (see online version for colours)

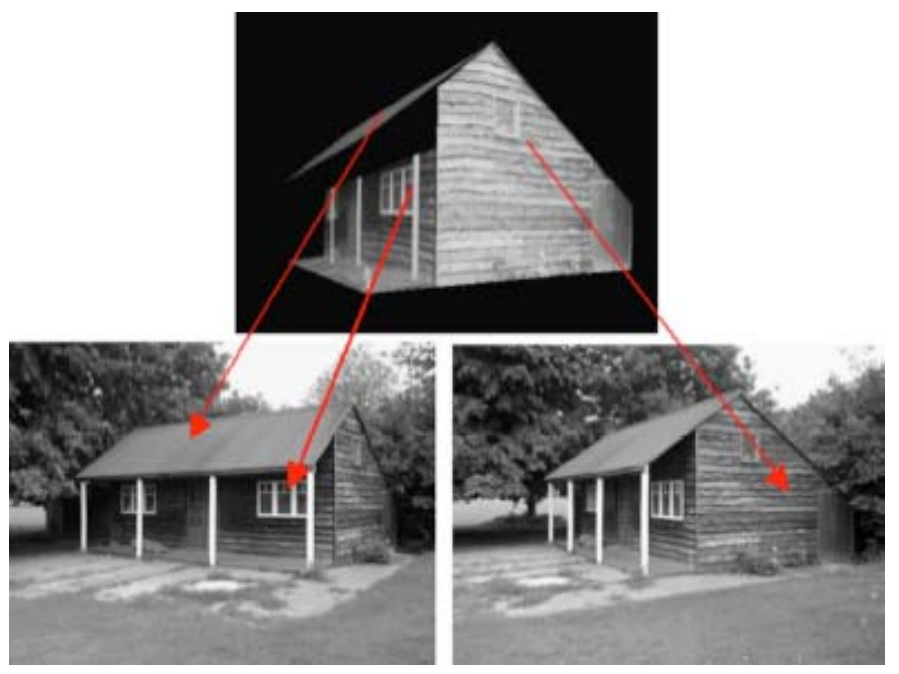

The seeing model in Figures 23-24 uses an object-reconstruction algorithm to detect three-dimensional objects in images. The object-reconstruction algorithm uses camera parameter estimation, key-point selection and hierarchical matching algorithms to determine viewpoints, select key-points, match key-points and detect three-dimensional objects in images (Zimmer and Miteran, 2001; Lu and Smith, 2006).

Figure 25 An object-tracking algorithm

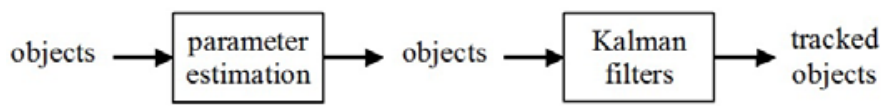


Figure 26 A three-dimensional object in images (see online version for colours)

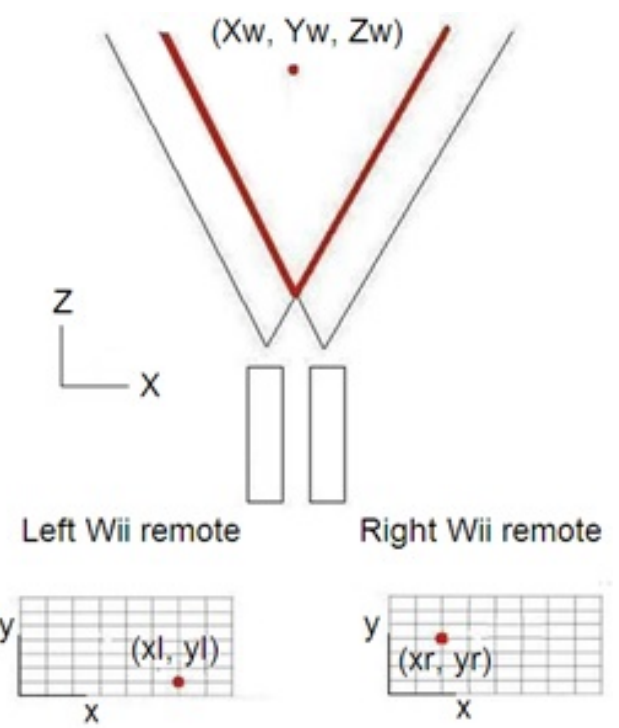

The seeing model in Figures 25-26 uses an object-tracking algorithm to track three-dimensional objects in images. The object-tracking algorithm uses a camera parameter estimation algorithm and Kalman filters to determine viewpoints, detect three-dimensional objects and track three-dimensional objects in images (Kao and Smith, 2011).

Figure 27 A microphone (see online version for colours)

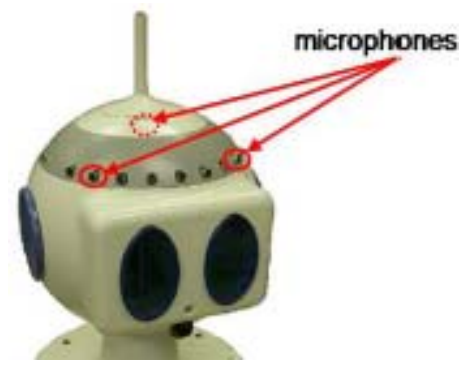

The hearing model in Figure 27 uses microphones to capture sounds. The microphones use sound pressure level transducers and electrical wires to detect sound-wave induced vibrations, convert sound-wave induced vibrations into electrical signals, transmit electrical signals and capture sounds (Lee et al., 2014).

The hearing model in Figure 28 uses a biomimetic ear to capture sounds. The biomimetic ear uses an ear simulator, a receiver microphone, a microphone preamplifier, a power supply and electrical wires to amplify sound waves, detect sound-wave induced vibrations, convert sound-wave induced vibrations into electrical signals, amplify electrical signals, transmit electrical signals and capture sounds (Bravo et al., 2008). 
Figure 28 A biomimetic ear

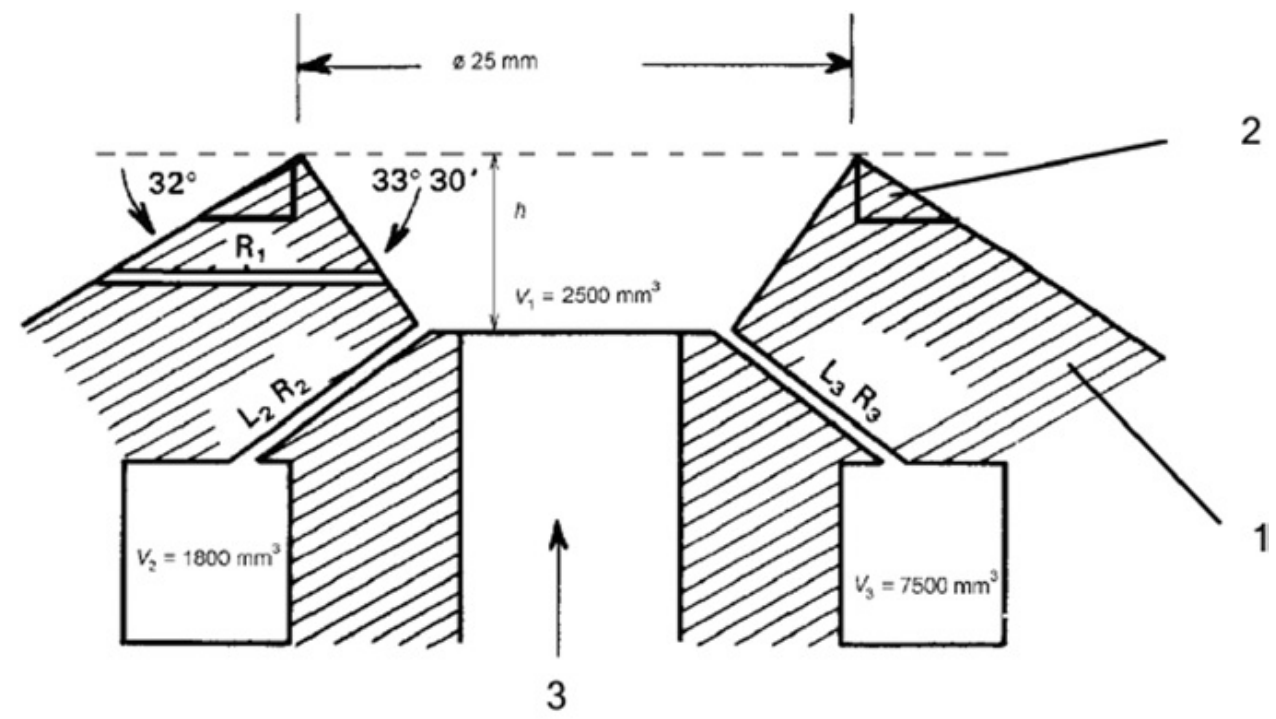

1 Ear simulator

2 Removable section

3 Microphone

IEC $868 / 98$

Figure 29 A sound localisation algorithm

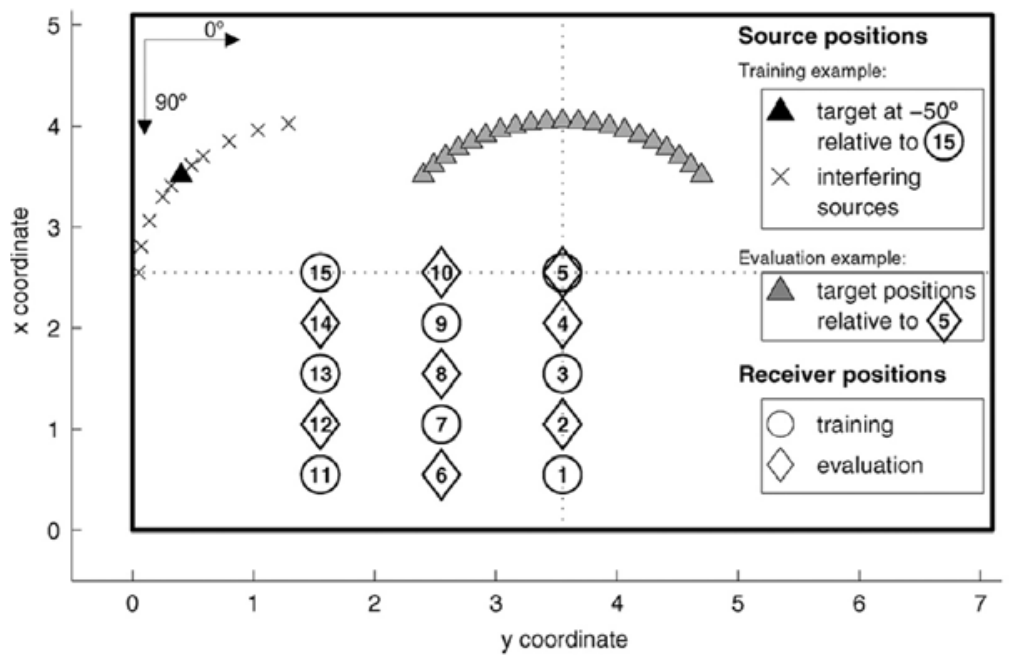

The hearing model in Figure 29 uses a sound-localisation algorithm to detect the locations of objects from sounds. The sound localisation algorithm uses receivers, ILDs (interaural level differences), IPDs (interaural phase differences) and GMMs (Gaussian mixture models) to detect sound levels, detect sound phases, detect sound souces and detect the locations of objects from sounds (May et al., 2011). 
Figure 30 A speech recognition algorithm

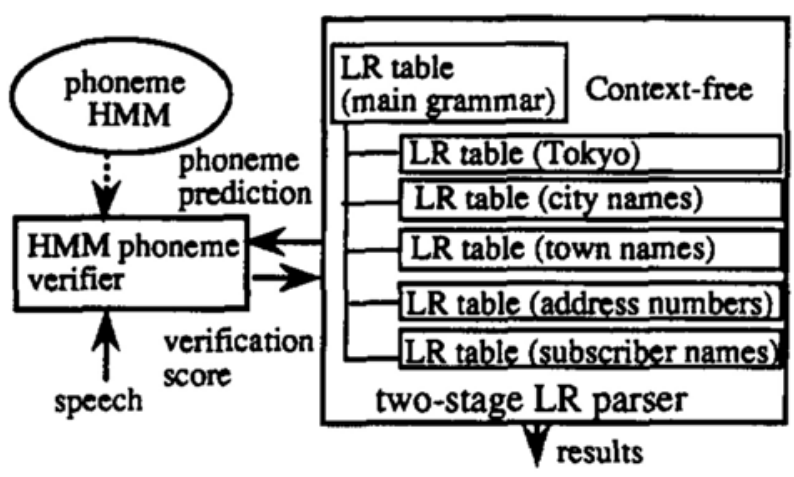

The hearing model in Figure 30 uses a speech-recognition algorithm to detect words from sounds. The speech recognition algorithm uses HMMs (hidden Markov models) and LR parsers (language-recognition parsers) to detect phonemes from sounds and detect words from sounds (Minami et al., 1995).

Figure 31 A biomimetic finger (see online version for colours)

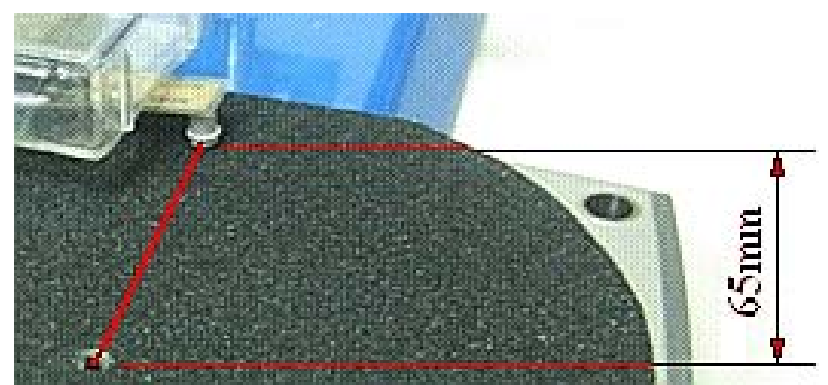

The touching model in Figure 31 uses a biomimetic finger to detect vibrations. The biomimetic finger uses an artificial finger and a vibration sensor to contact physical objects and detect vibrations (Smith et al., 2012b).

Figure 32 The amplitudes of a vibration (see online version for colours)

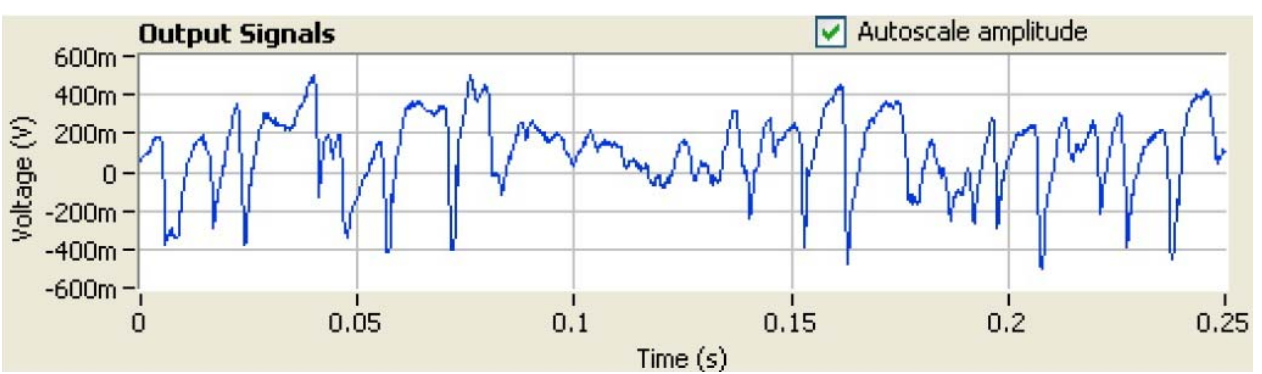


Figure 33 The frequencies of a vibration

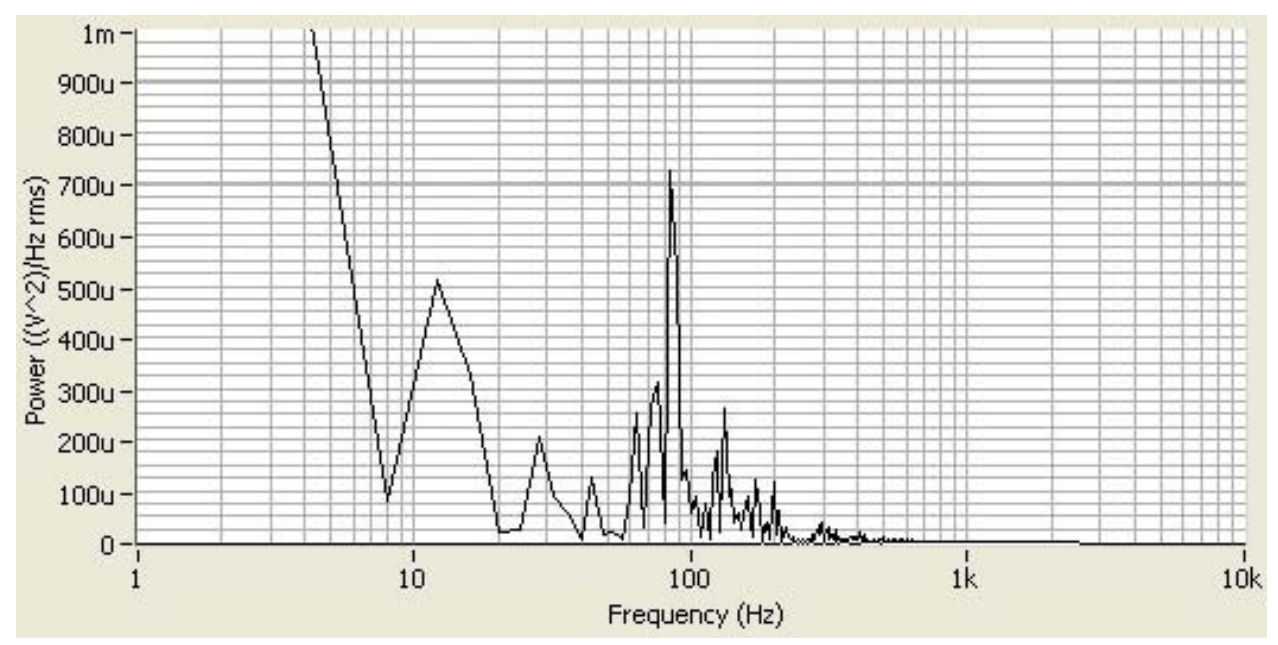

The touching model in Figures 32-33 uses an object-recognition algorithm to detect objects from vibrations. The object-recognition algorithm uses Fourier transforms to detect the amplitudes of vibrations, to detect the frequencies of vibrations and to detect objects from vibrations (Smith et al., 2012b).

Figure 34 A chemical taste sensor

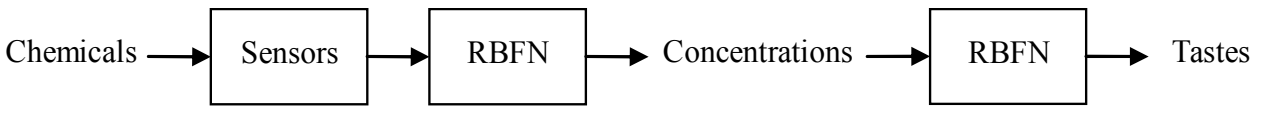

The tasting model in Figure 34 uses a chemical taste sensor to detect tastes from chemical concentrations. The chemical taste sensor uses an array of electrochemical sensors and two-stage RBFNs (radial basis function networks) to detect chemical concentrations and to detect tastes from chemical concentrations (Ishihara et al., 2005).

Figure 35 Two information processing models

\section{Model $\alpha$}

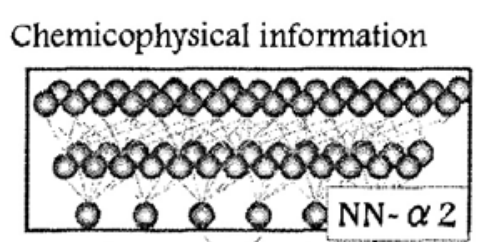

Sensory information

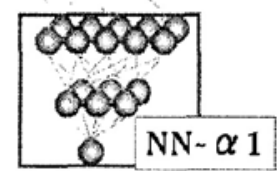

Taste evaluation
Model $\beta$

Chemicophysical information

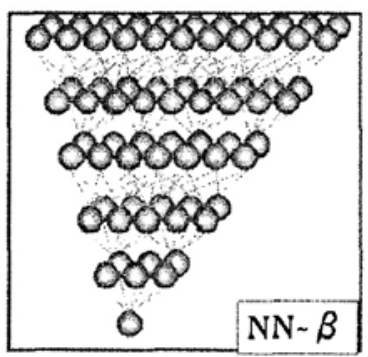

Taste evaluation 
The tasting model in Figure 35 uses two information processing models (model $\alpha$, model $\beta$ ) to detect objects from tastes. The two information processing models (model $\alpha$, model $\beta$ ) use three neural networks $(\mathrm{NN}-\alpha 1, \mathrm{NN}-\alpha 2, \mathrm{NN}-\beta)$ to detect sensory information from chemicophysical information, to detect tastes from chemicophysical information and to detect objects from tastes (Oguri et al., 2000).

Figure 36 A biomimetic sensor (see online version for colours)

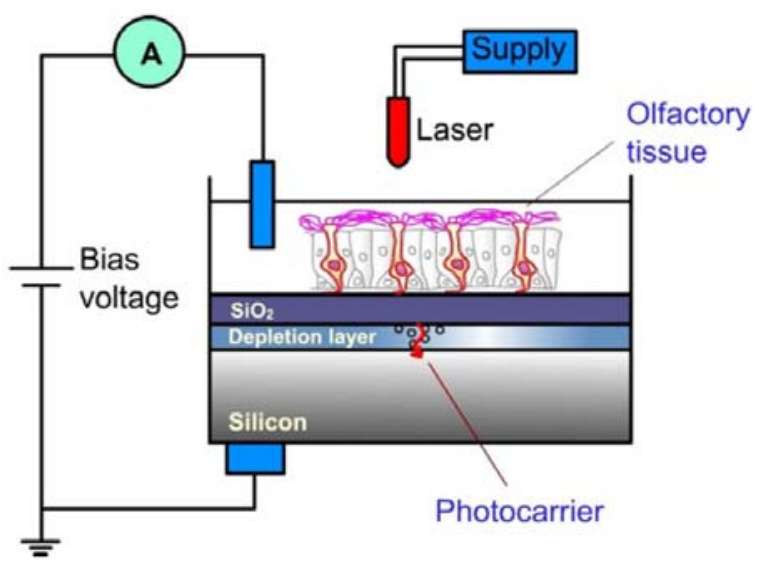

The smelling model in Figure 36 uses a biomimetic sensor to detect smells from odour-induced electrical signals in human olfactory tissue. The biomimetic sensor uses human olfactory tissue, LAPS (light-addressable potentiometric sensors), power supplies and principal component analysis to create odour-induced electrical signals in human olfactory tissue, to group odour-induced electrical signals in human olfactory tissue into smells and to detect smells from odour-induced electrical signals (Liu et al., 2010).

Table 1 Two object recognition algorithms

\begin{tabular}{lccc}
\hline \multicolumn{3}{c}{ Classification accuracies on the 'photo' set, using Euclidean metric } \\
\hline \multirow{2}{*}{ Representation space } & \multicolumn{2}{c}{ Parameters } & $\begin{array}{c}\text { Classification } \\
\text { accuracy (\%) }\end{array}$ \\
\cline { 2 - 4 } Standard & $\sigma$ & $C$ & 78.76 \\
$S_{T}$ & 0.02 & 200 & 90.52 \\
\hline
\end{tabular}

The smelling model in Table 1 uses two object-recognition algorithms to detect objects from smells. The two object recognition algorithms (the 'Standard' and ' $S_{T}$ ' object-recognition algorithms) use features and a Euclidean metric to detect objects (the ‘photo' set) from smells (Bicego, 2005).

\subsubsection{Eight thinking, relating, or associating models}

Table 2 and Figures 37-47 show eight thinking (communicating, remembering, deciding, solving, or learning), relating (selecting, matching, or transforming), or associating (selecting, matching, or transforming) models. 
Table 2 User feelings about objects

\begin{tabular}{lcc}
\hline Elegant & - & Ordinary \\
Simple & - & Complex \\
High tech & - & Traditional \\
Luxurious & - & Basic \\
Beautiful & - & Plain \\
Unique & - & Common \\
\hline
\end{tabular}

Figure 37 Design elements of objects (see online version for colours)

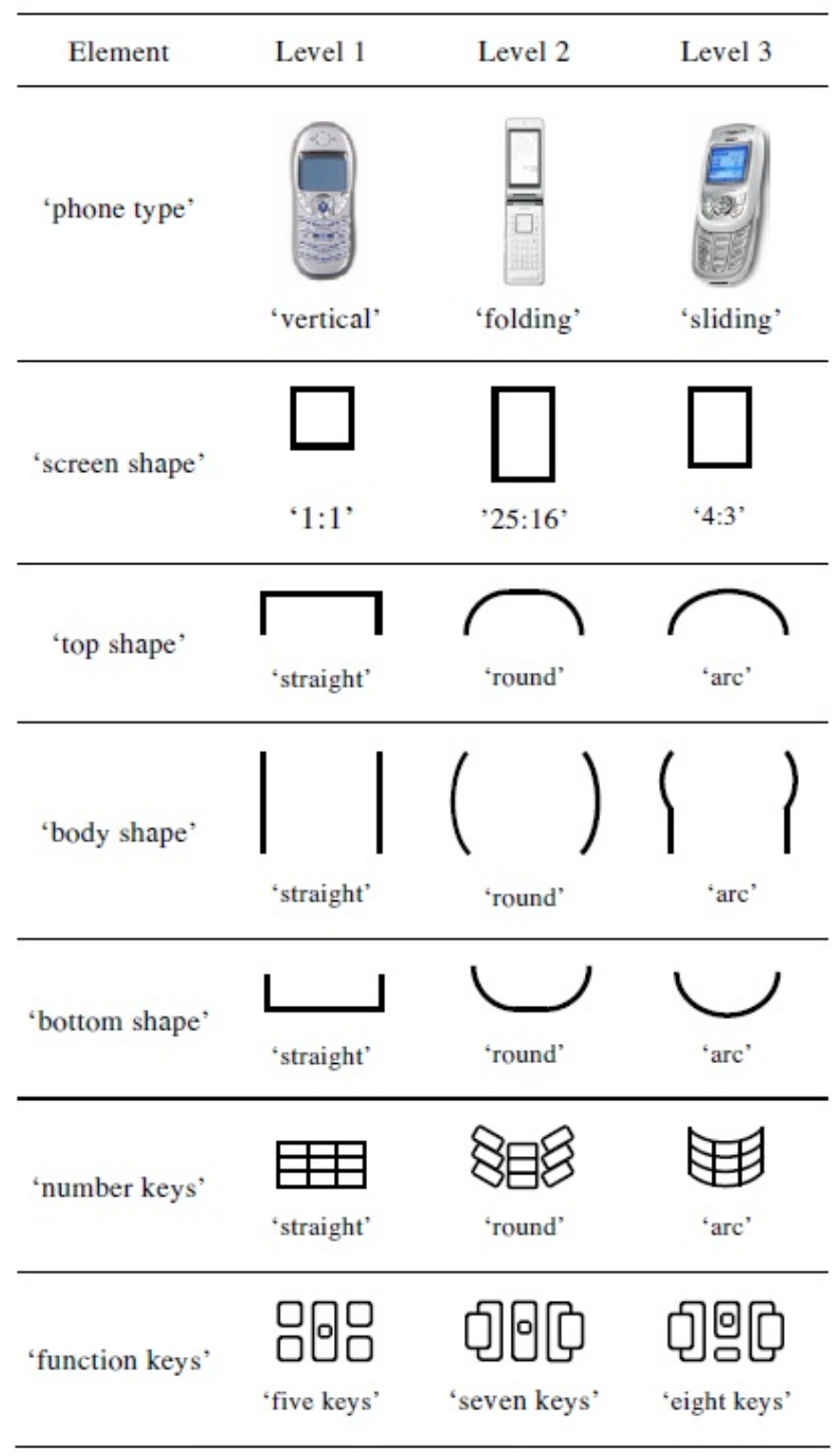


The communicating model in Table 2 and Figure 37 uses selected words to communicate information about objects. The selected words are used to communicate user feelings about objects and design elements of objects (Smith and Smith, 2012).

Figure 38 A framework for creating information models

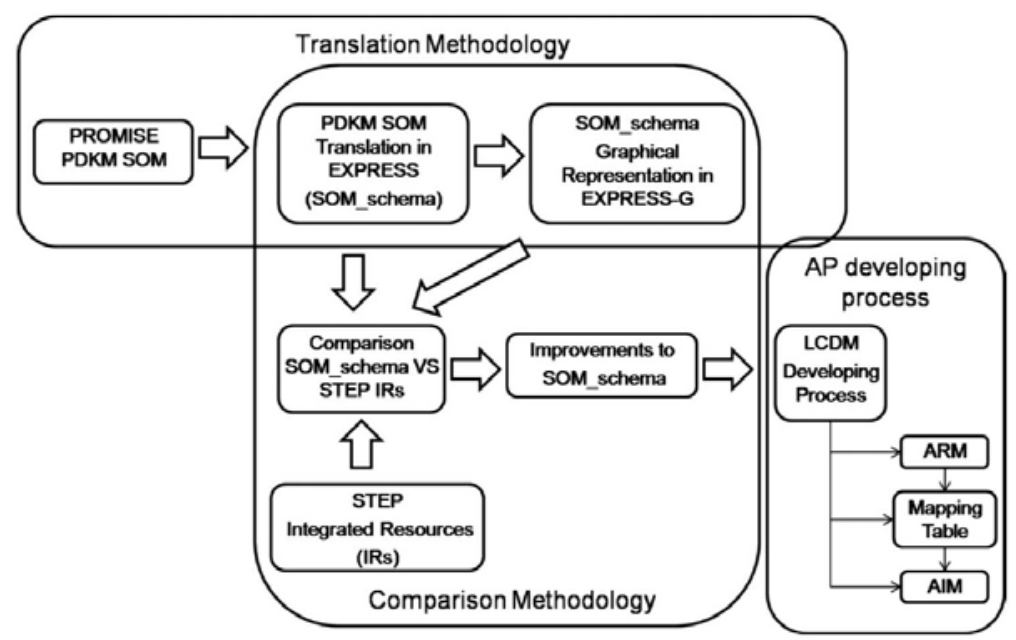

The remembering model in Figure 38 uses a framework and information models to define, store and recall information about objects. The framework uses translation methods, comparison methods and integrating methods to translate information about objects into ontologies, compare ontologies to information requirements, integrate ontologies into information models and use information models to define, store and recall information about objects (Taisch et al., 2011).

Table 3 A survey

\begin{tabular}{|c|c|c|c|c|c|c|c|c|}
\hline & 1 & & & 4 & & & 7 & \\
\hline Elegant & $\square$ & $\square$ & $\square$ & $\square$ & $\square$ & $\square$ & $\square$ & Ordinary \\
\hline Simple & $\square$ & $\square$ & $\mathbf{\square}$ & $\square$ & $\square$ & $\square$ & $\square$ & Complex \\
\hline High tech & $\square$ & $\square$ & $\square$ & घ & $\square$ & $\square$ & $\square$ & Traditional \\
\hline Luxurious & $\square$ & $\square$ & घ & $\square$ & $\square$ & $\square$ & $\square$ & Basic \\
\hline Beautiful & $\square$ & $\square$ & घ & $\square$ & $\square$ & $\square$ & $\square$ & Plain \\
\hline Unique & $\square$ & $\square$ & $\mathbf{\square}$ & $\square$ & $\square$ & $\square$ & $\square$ & Common \\
\hline
\end{tabular}

Figure 39 A semantic space

\begin{tabular}{l|llll}
\hline$M_{v}$ & $=$ & $T$ & $S$ & $D_{v}{ }^{\prime}$ \\
\hline & & & & \\
& & & & \\
\hline
\end{tabular}


The deciding model in Table 3 and Figure 39 uses surveys, semantic spaces and matching methods to make decisions about objects. The surveys use terms to describe customer needs. The semantic spaces use term-by-design matrices $\{M\}$, term matrices $\{T\}$, scaling factor matrices $\{S\}$ and design matrices $\{D\}$ to describe designs. The matching methods use the surveys and semantic spaces to create customer need vectors $\left\{M_{v}\right\}$, project customer need vectors $\left\{M_{v}\right\}$ into semantic spaces $\{T, S, D\}$ and match projected customer need vectors $\left\{D_{v}\right\}$ to projected design vectors $\{D\}$ in semantic-spaces $\{T, S, D\}$ (Smith and Smith, 2012).

Figure 40 An object

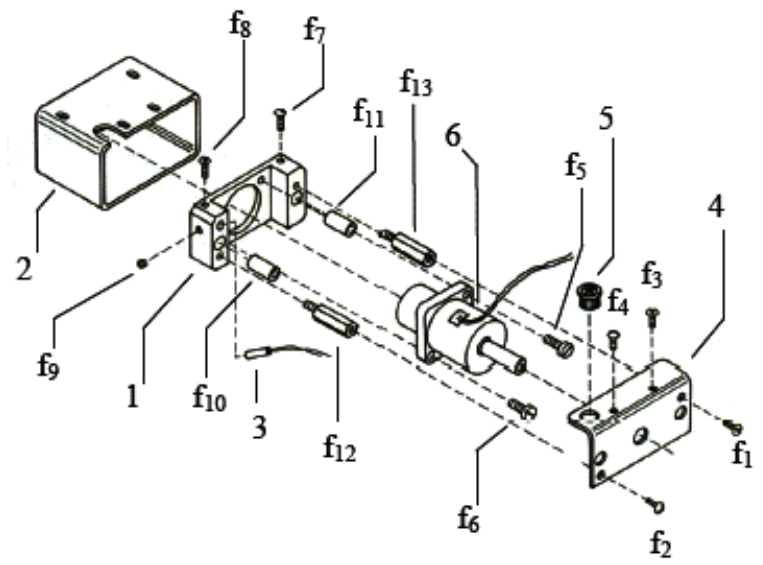

Figure 41 A disassembly sequence structure graph

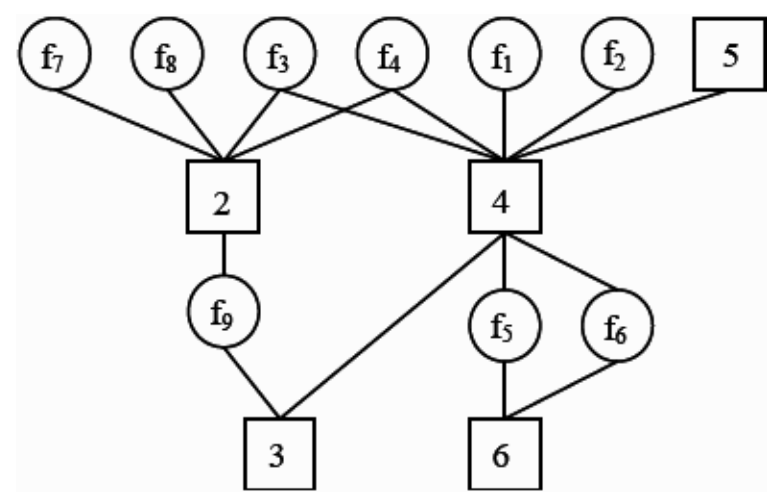

The solving model in Figures 40-41 uses a graph-searching algorithm to create disassembly plans for objects. The graph-searching algorithm uses disassembly sequence structure graphs and constraint matrices to model objects and the relationships between parts in objects. The graph-searching algorithms use rules to search the disassembly sequence structure graphs and constraint matrices to create disassembly plans for objects (Smith et al., 2012a). 
Figure 42 A sequence-learning algorithm

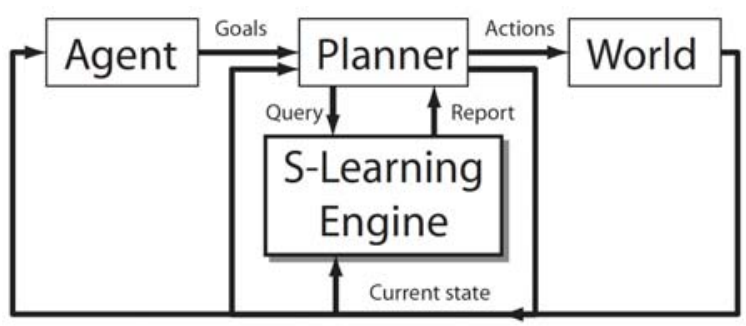

Figure 43 A task related to objects (see online version for colours)

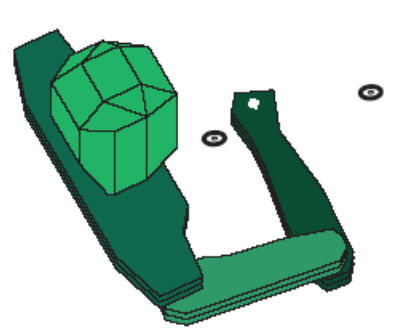

Figure 44 Circulatory system responses for flight safety simulations

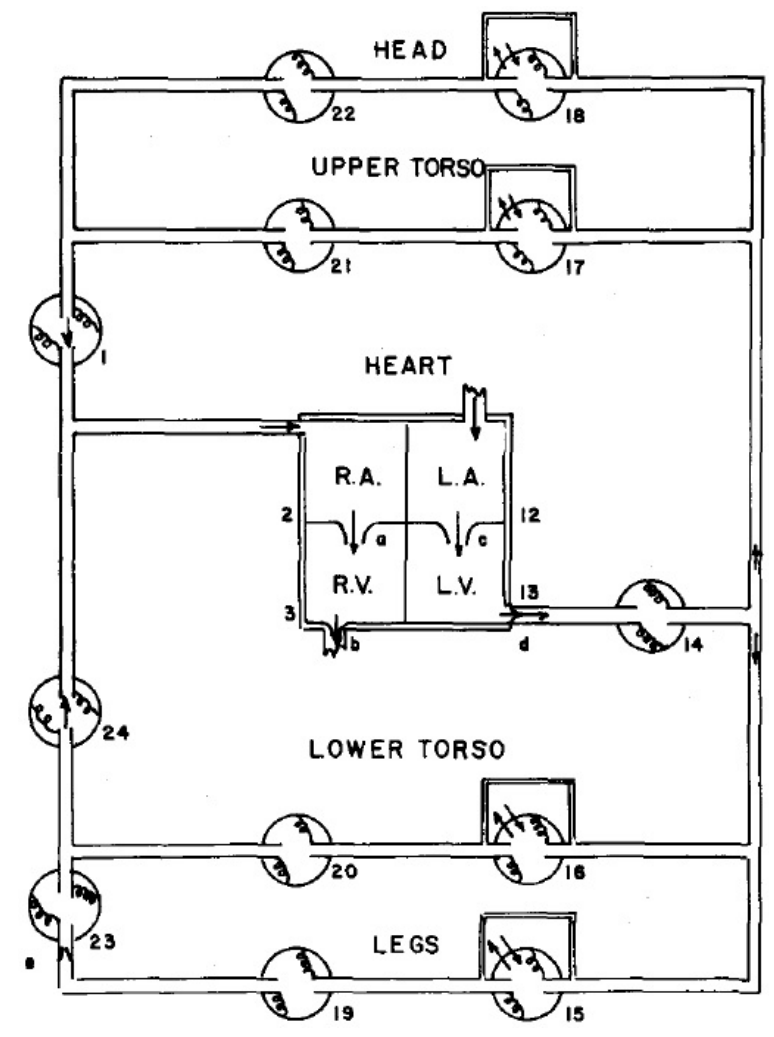


The learning model in Figures 42-43 uses a sequence-learning algorithm to learn tasks related to objects. The sequence-learning algorithm uses sensors, an agent and a planner to capture signals, set goals, choose actions and learn tasks related objects (Rohrer, 2007).

The selecting model in Figure 44 uses environmental conditions (pressures, accelerations and forces) and differential equations to select circulatory system responses (pressures, flows and volumes) for flight safety simulations (Hardy et al., 1982).

Figure 45 Molecular theory principles<smiles>CCc1ccccc1</smiles>

Styrene<smiles>C=Cc1ccc(C=C)cc1</smiles>

Divinyl Benzene<smiles>C=C[Co]OC(=O)O</smiles><smiles>O=C(OOC(=O)c1ccccc1)c1ccccc1</smiles>

Vinyl

Neodecanoate
Benzoyl Peroxide

The matching model in Figure 45 uses molecular theory principles to match induced environmental conditions to molecular movements in molecular structures $(\mathrm{Nji}$ and $\mathrm{Li}$, 2010).

Figure 46 Atomic theory equations (see online version for colours)

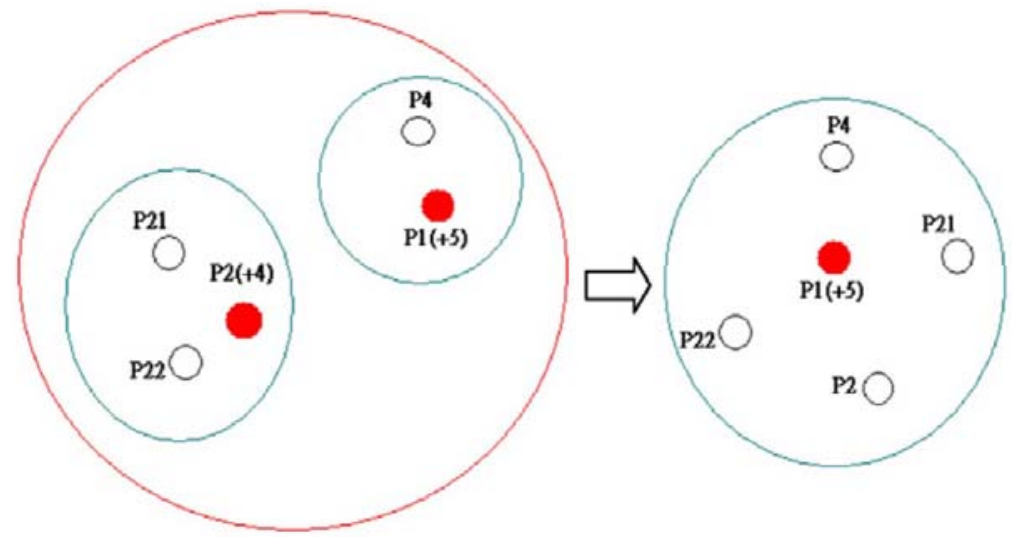

The transforming model in Figure 46 uses atomic theory equations to transform natural environmental conditions (atomic charges and distances) into atomic movements in atomic structures (Smith and Yen, 2010).

\subsubsection{Five acting, responding, or organising models}

Figures 47-51 show five acting (speaking, grasping, or moving), responding (generating, or modifying), or organising (creating, or modifying) models.

The speaking model in Figure 47 uses a speech processing programme to transform speech into synthesised speech for speaking tasks. The speech processing programme uses mel-cepstral analysis, a hidden Markov model (HMM) encoder, a hidden Markov model (HMM) decoder and a mel-log spectrum approximation (MLSA) filter to 
transform and encode speech into pitch, phoneme sequence and state duration vectors or decode and filter pitch, phoneme sequence and state duration vectors into synthesised speech for speaking tasks (Tokuda et al., 1998).

Figure 47 A speech processing programme

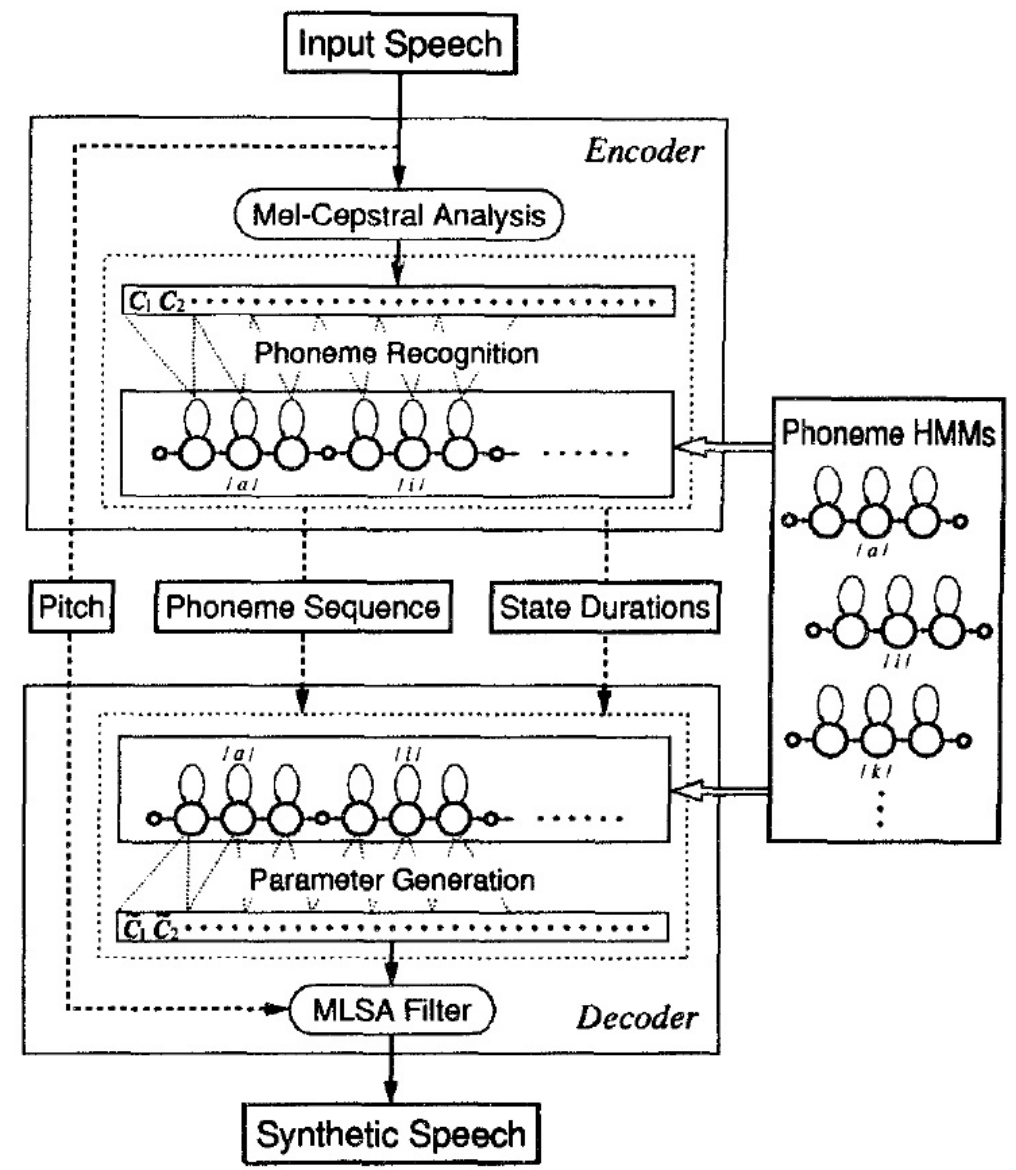

Figure 48 A motion planning programme (see online version for colours)

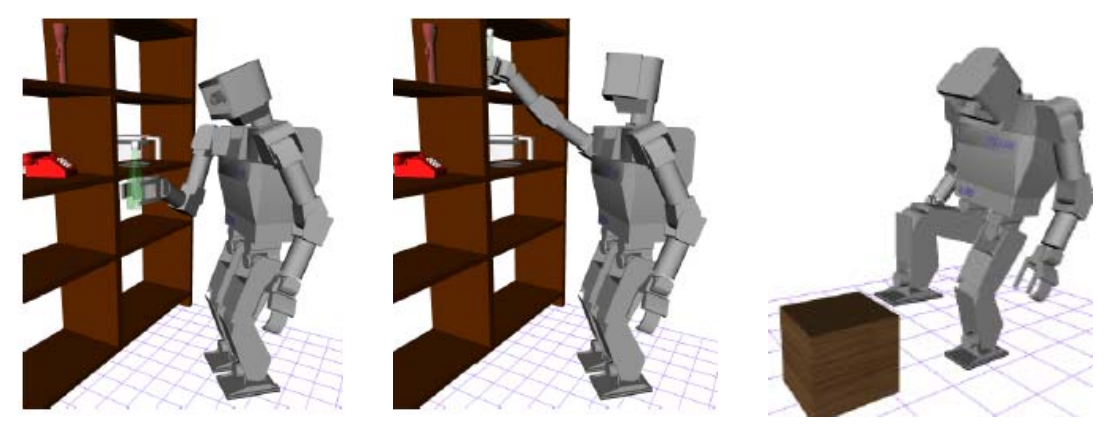


The grasping and moving model in Figure 48 uses a motion planning programme to plan motions for grasping and moving tasks. The motion planning programme uses search trees, dynamic programming algorithms and trajectory generation algorithms to plan motions for grasping and moving tasks (Kuffner et al., 2003).

Figure 49 A bio-signals programme

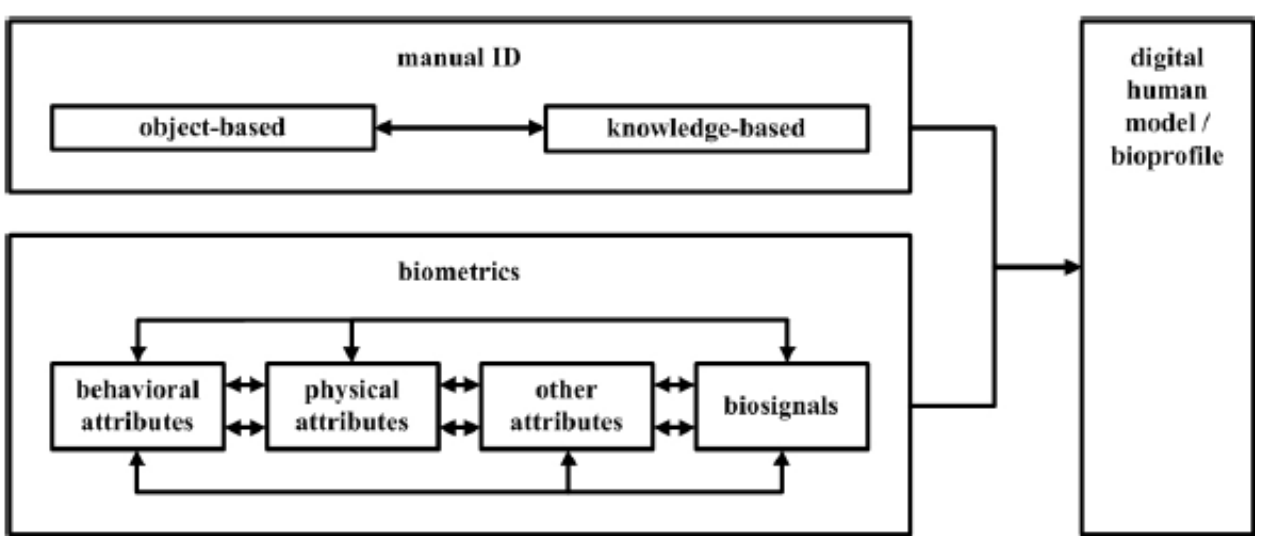

The generating model in Figure 49 uses a bio-signals programme to generate electrocardiograms (ECGs), electromyograms (EMGs) and electrodermal activity signals (EDAs) for biometric identifications. The bio-signals programme uses stored electrocardiograms (ECGs), electromyograms (EMGs) and electrodermal activity signals (EDAs) to generate electrocardiograms (ECGs), electromyograms (EMGs) and electrodermal activity signals (EDAs) for biometric identifications (van den Broek, 2010).

Figure 50 An ergonomic effects programme (see online version for colours)

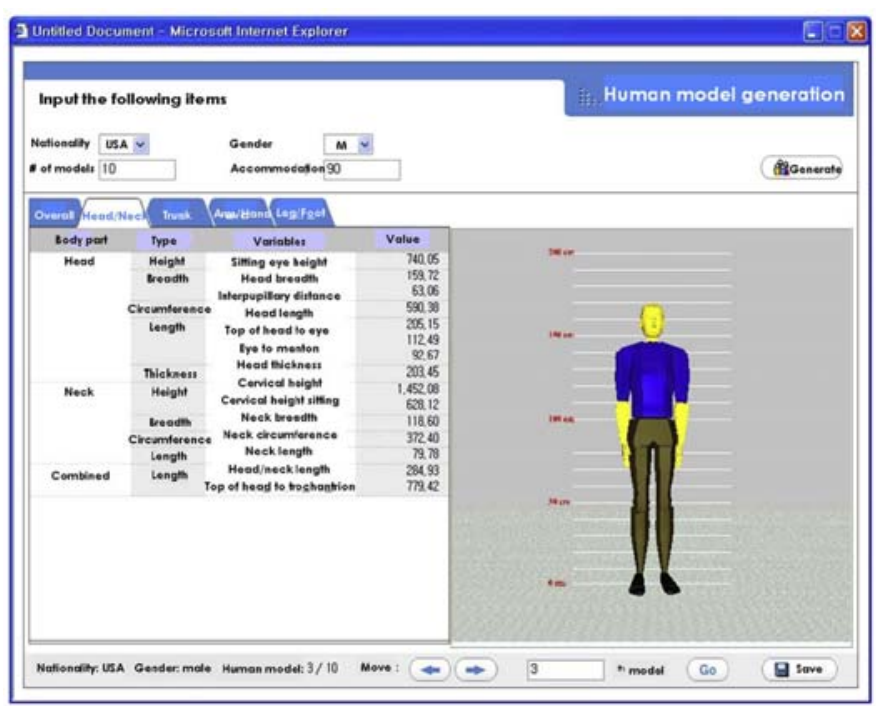


The creating model in Figure 50 uses an ergonomics programme to create ergonomic models for ergonomic analysis tasks. The ergonomic programme uses personal attributes (nationalities, genders, weights and statures) to create ergonomic models for ergonomic analysis tasks (Demirel and Duffy, 2007a, 2007b; Jung et al., 2009; Wu et al., 2011; De Magistris et al., 2013).

Figure 51 An anthropometrical models programme

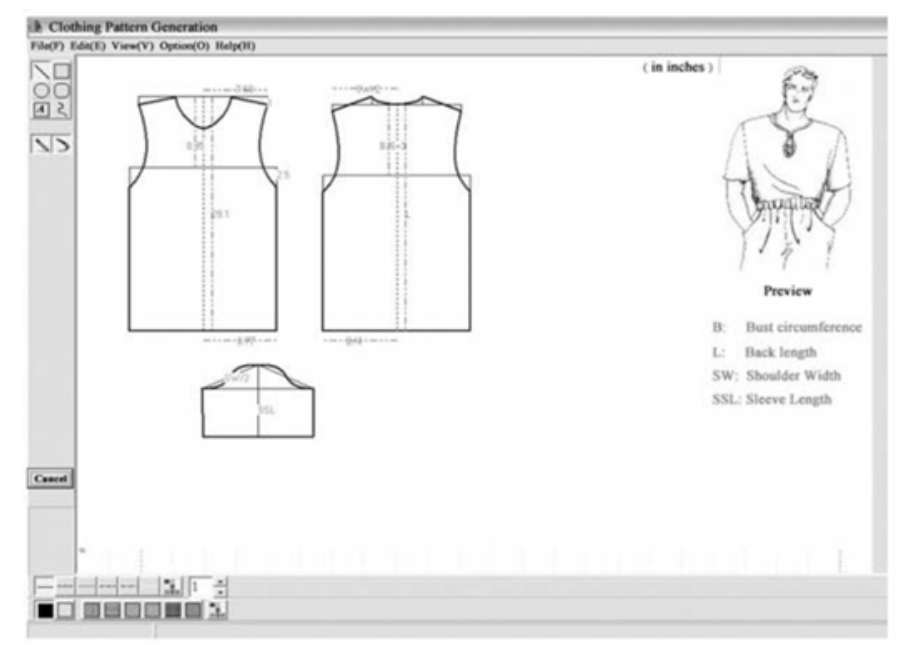

The modifying model in Figure 51 uses an anthropometrical models programme to modify anthropometrical models for clothing design tasks. The anthropometrical models programme uses 3D laser scanner measurements and anthropometrical landmarks to modify anthropometrical models for clothing design tasks (Lu et al., 2010).

\section{Conclusions}

This study describes digital human models. This study also describes trends in digital human models, shows that the most important trend in digital human models is integrated digital human models, shows that integrated digital human models are frameworks and models and describes frameworks and models that can be used to create digital human models.

The results show that digital human models are models, programmes, or devices, theoretical, analytical, or physical models and behavioural, functional, or structural models which can be used to study, analyse, or duplicate human behaviours, functions, or structures. The results show that digital human models are integrated or individual models which consist of frameworks and models or models.

The results can be used to describe, select, or create digital human models. The results can be used to describe, select, or create integrated models. Therefore, the results can be used to describe, select, or create frameworks and models. The results can also be used to describe, select, or create individual models. Therefore, the results can also be used to describe, select, or create models. 


\section{References}

Bicego, M. (2005) 'Odor classification using similarity-based representation', Sensors and Actuators, Vol. B 100, No. 2, pp.225-230.

Bravo, A., Barham, R., Ruiz, M., Lopez, J., De Arcas, G. and Recuero, M. (2008) 'A new 3D finite element model of the IEC 60318-1 artificial ear', Metrologia, Vol. 45, No. 4, pp.448-458.

Cangley, P., Passfield, L., Carter, H. and Bailey, M. (2012) 'A model for performance enhancement in competitive cycling', Movement and Sport Science, Vol. 1, No. 75, pp.59-71.

Carruth, D., Thomas, M, Robbins, B., Morais, A. (2007) 'Integrating perception, cognition, and action for digital human modeling', Lecture Notes in Computer Science, Vol. 4561, pp.333-342.

Choi, J., Son, H. and Lee, Y. (2008) 'Design of a biomimetic robot-eye system with single vari-focal lens and winding-type SMA actuator', International Conference on Control, Automation, and Sustems, pp.2533-2537.

De Magistris, G., Micaelli, A., Evrard, P., Andriot, C., Savin, J., Gaudez, C., Marsot, J. (2013) 'Dynamic control of DHM for ergonomic assessments', International Journal of Industrial Ergonomics, Vol. 43, No. 2, pp.170-180.

Demirel, H. and Duffy, V. (2007a) 'Digital human modeling for product lifecycle management', Lecture Notes in Computer Science, Vol. 4561, pp.372-381.

Demirel, H. and Duffy, V. (2007b) 'Applications of digital human modeling in industry', Lecture Notes in Computer Science, Vol. 4561, pp.824-832.

Hardy, H., Collins, R. and Calvert, R. (1982) 'A digital computer model of the human circulatory system', Medical and Biological Engineering and Computing, Vol. 20, No. 5, pp.550-564.

Hsu, C. and Chen, C. (2012) 'Speaker-dependent model interpolation for statistical emotional speech synthesis', European Association for Signal Processing Journal on Audio, Speech, and Music Processing, No. 1, pp.1-10.

Ishihara, S., Ikeda, A., Citterio, D., Maruyama, K., Hagiwara, M. and Suzuki, K. (2005) 'Smart chemical taste sensor for determination and prediction of taste qualities based on a two-phase optimized radial basis function network', Analytical Chemistry, Vol. 77, No. 24, pp.7908-7915.

Iwata, H. and Sugano, S. (2009) 'Design of human symbiotic robot Twendy-One', International Conference on Robotics and Automation, pp.580-586.

Jiang, Z. and Mangharam, R. (2013) 'University of Pennsylvania develops electrophysiological heart model for real-time closed-loop testing of pacemakers', Mathworks, pp.1-4.

Jung, K., Kwon, O. and You, H. (2009) 'Development of a digital human model generation method for ergonomic design in virtual environment', International Journal of Industrial Ergonomics, Vol. 39, No. 5, pp.744-748.

Kao, Y. and Smith, S. (2011) 'Dynamic tracking of infrared points in a three-dimensional space', International CAD Conference and Exhibition, Paper No. 105.

Kolesnikov-Jessop, S. (2012) 'Automatons and ingenuity', The New York Times, 8 March.

Kuffner, J., Nishiwaki, K., Kagami, S., Inaba, M. and Inoue, H. (2003) 'Motion planning for humanoid robots', International Symposium of Robotics Research, pp.1-10.

Lee, S., Park, Y. and Choi, J. (2014) 'Estimation of multiple sound source directions using artificial robot ears', Applied Acoustics, Vol. 77, pp.49-58.

Liu, Q., Ye, W., Hu, N., Cai, H., Yu, H. and Wang, P. (2010) 'Olfactory receptor cells respond to odors in a tissue and semiconductor hybrid neuron chip', Biosensors and Bioelectronics, Vol. 26, No. 4, pp.1672-1678.

$\mathrm{Lu}$, J., Wang, M., Chen, C. and Wu, J. (2010) 'The development of an intelligent system for customized clothing making', Expert Systems with Applications, Vol. 37, No. 1, pp.799-803.

Lu, Y. and Smith, S. (2006) 'A comprehensive tool for recovering 3D models from 2D photos', Journal of Computing and Information Science in Engineering, Vol. 6, No. 4, pp.372-380. 
Maldonado-Bascon, S., Lafuente-Arroyo, S., Gil-Jiménez, P., Gomez-Moreno, H. and Lopez-Ferreras, F. (2007) 'Road-sign detection and recognition based on support vector machines', IEEE Transactions on Intelligent Transportation Systems, Vol. 8, No. 2, pp.264-278.

May, T., van de Par, S. and Kohlrausch, A. (2011) 'A probabilistic model for robust localization based on binaural auditory front-end', IEEE Transactions on Acoustics, Speech, and Language Processing, Vol. 18, No. 1, pp.1-13.

Mellman, H. and Xu, Y. (2010) 'Adaptive motion control with visual feedback for a humanoid robot', International Conference on Intelligent Robots and Systems, pp.3170-3174.

Miller, A., Marsh, J., Reeve, A., Garny, A., Britten, R., Halstead, M., Cooper, J., Nickerson, D. and Nielsen, P. (2010) 'An overview of the CellML API and its implementation', BMC Bioinformatics, Vol. 11, No. 178, pp.1-12.

Minami, Y., Shikano, K., Takahashi, S., Yamada, T., Yoshioka, O. and Furui, S. (1995) 'A large-vocabulary continuous speech recognition algorithm applied to a multi-modal telephone directory assistance system', Speed Communication, Vol. 15, Nos. 3-4, pp.301-310.

$\mathrm{Nji}$, J. and Li, G. (2010) 'A biomimic shape memory polymer based self-healing particulate composite', Polymer, Vol. 51, No. 25, pp.6021-6029.

Noble, D., Garny, A. and Noble, P. (2012) 'How the Hodgkin-Huxley equations inspired the cardiac physiome project', Journal of Physiology, Vol. 590, No. 11, pp.2613-2628.

Oguri, K., Sugimoto, T. and Iwata, A. (2000) 'A gustatory information processing model for the evaluation of taste preference', International Joint Conference on Neural Networks, Vol. 1, pp.234-239.

Rodic, A., Katic, D. and Mester, G. (2009) 'Ambient intelligent robot-sensor networks for environmental surveillance and remote sensing', The 7th International Symposium on Intelligent Systems and Informatics, pp.39-44.

Rohrer, B. (2007) 'S-learning: a biomimetic algorithm for learning, memory, and control in robots', IEEE Conference on Neural Engineering, pp.148-151.

Smith, G. and Smith, S. (2011) Method for Recognizing Objects in Images, pp.1-17, US Patent: 2011/0081081.

Smith, G. and Smith, S. (2012) 'Latent semantic engineering - a new conceptual user-centered design approach', Advanced Engineering Informatics, Vol. 26, No. 2, pp.456-473.

Smith, S. and Yen, C. (2010) 'Green product design through product modularization using atomic theory', Robotics and Computer-Integrated Manufacturing, Vol. 26, No. 6, pp.790-798.

Smith, S., Smith, G. and Chen, W. (2012a) 'Disassembly sequence structure graphs: an optimal approach for multiple-target selective disassembly sequence planning', Advanced Engineering Informatics, Vol. 26, No. 2, pp.306-316.

Smith, S., Smith, G. and Lee, J. (2012b) 'A realistic portable tactile haptic device', Proceedings of TMCE, pp.7-11.

Tachiwana, H., Kagawa, W., Shiga, T., Osakabe, A., Miya, Y., Saito, K., Hayashi-Takanaka, Oda, T., Sato, M., Park, S., Kimura, H. and Kurumizaka, H. (2011) 'Crystal structure of the human centromeric nucleosome containing CENP-A', Nature, Vol. 476, No. 7359, pp.232-235.

Taisch, M., Cammarino, B. and Cassina, J. (2011) 'Lifecycle data management: first step towards a new product lifecycle management standard', International Journal of Computer Integrated Manufacturing, Vol. 24, No. 12, pp.1117-1135.

Tokuda, K., Masuko, T., Hiroi, J., Kobayashi, T. and Kitamura, T. (1998) 'A very low bit rate speech coder using HMM-based speech recognition/synthesis techniques', International Conference on Acoustics, Speech and Signal Processing, Vol. 2, pp.609-612.

van den Broek, E. (2010) 'Beyond biometrics', International Conference on Computational Science, pp.2511-2519.

Waurzyniak, P. (2013) 'Getting the most out of your automation purchase', Manufacturing Engineering, December, pp.57-65. 
Wu, T., Tian, R. and Duffy, G. (2012) 'Performing ergonomics analyses through virtual interactive design: validity and reliability assessment', Human Factors and Ergonomics in Manufacturing and Service Industries, Vol. 22, No. 3, pp.256-268.

Zimmer, J. and Miteran, J. (2001) 'Face modeling: a real-time embedded implementation of a stereovision algorithm', Proceedings of the SPIE, pp.155-162. 